\title{
The exploration application of MIKE SHE model in Qingtongxia irrigation area water recycle*
}

\author{
Jun-Tao Wang, Hui-Min Zhang and Bu-Hui Chang \\ Yellow River Institute of Hydraulic Research, YRCC \\ Henan Zhengzhou, 450003, China \\ E-mail:wjt4317@163.com
}

\begin{abstract}
The water diversion-transportation-drainage-return had become the dominant regional hydrological processes in Qingtongxia irrigation area. For the reason of systematically mastering water cycle rules of Qingtongxia irrigation area, this study chose MIKE SHE distributed hydrological model with physical basis to build water-cycle model of Qingtongxia irrigation area, calculated the parameters with data of underground water level and drainage flow from 2007 to 2009, and validated the parameters with same data from 2010 to 2012. Using this model, this study simulated and analyzed the conversion relationship of different water cycle factors in Qingtongxia irrigation area. The results shown that annual average evapotranspiration was 3.537 billion $\mathrm{m}^{3}$, total drainage ditches flow was about 2.832 billion $\mathrm{m}^{3}$, and the groundwater runoff into Yellow River was about 55 million $\mathrm{m}^{3}$. This study firstly quantitative clarified the relationship between recharge and discharge of Qingtongxia irrigation area and the Yellow River. These will lay the foundation for studying the water circulation evolution mechanism and water resources efficient utilization under changing environment.
\end{abstract}

Keywords: Qingtongxia irrigation area; water-cycle model; MIKE SHE model; parameter calibration

\section{Background}

Qingtongxia irrigation area locates in Ningxia of China, and its area is 4905.73 square kilometers. The Yellow River is the main source for its irrigation. In Ningxia, the average annual flow is $1030 \mathrm{~m}^{3} / \mathrm{s}$, and the average transit watercontent is 32 billion 500 million $\mathrm{m}^{3}$ [1]. This irrigation area has excellent diversion and drainage conditions, and its water withdrawal composition is very complex. The water cycle was influenced by precipitation, evaporation, infiltration and runoff et al in natural watershed, and also affected by tillage, water diversion, irrigation, drainage, water storage and groundwater exploitation et al. The impact of human activities on the original natural water cycle system

\footnotetext{
"This work was financially supported by Fundamental Research Funds for the State Level Research Institutes of Yellow River Institute of Hydraulic Research (HKY-JBYW-2016-44) and Special Fund for Scientific Research in the Public Interest of MWR (201401019).
} 
occurred great changes, replaced by the natural-artificial composite water circulation system under artificial and natural interaction. In less precipitation region, the water distribution under artificial affection had changed, and also the water circulation structure and characteristic parameters [2-4].

The impact of climate change and human activity on water cycle process has become one of the core contents and major issues in the study of global change [5-8]. At present, the human understanding of transformation of atmosphere water, surface water, soil water and groundwater in irrigation area under changing environment was poor, the research methods are also more concentrated in the traditional natural water-cycle model. And these severely restricted the irrigation area water resources regulation and the development of social economy.

\section{The Construction of Irrigation Area Distributed Hydrological Model}

\subsection{Structure and characteristics of MIKE SHE model}

MIKE SHE model in vertical mainly divided into three layers: the atmosphere, unsaturated soil land saturated soil layer. The atmosphere mainly describe the above-ground moisture migration; Unsaturated soil layer mainly represent the above-underground-water and the lithosphere for the underground water level drop; Saturated zone adopt the implicit finite difference numerical method, and the linear reservoir method for users to choose; Each vertical were stratified into convergence with MIKE 11 modules, and calculate the exchange of each layer and the river [9].

\subsection{Modeling Method}

(1) Model range and surface elevation. In this study, we chose $90 \mathrm{~m} \times 90 \mathrm{~m}$ digital elevation map as foundation. Considering the large research scope and the dual constraints of simulation accuracy, we selected $1 \mathrm{~km} \times 1 \mathrm{~km}$ grid space data and run the model.

(2) Rainfall and evaporation sub modules. This study selected rainfall data of 20 rainfall stations and $\mathrm{ET}_{0}$ data of 5 weather stations to make rainfall distribution polygon using the Thiessen polygon method, and import the results into MIKE SHE model.

(3) Land use sub modules. This study divided the irrigation area into farmland, woodland, grassland, water, urban and rural, sandy wasteland with land use compos graph of 2005, and their proportion was $21.9 \%, 5.4 \% 46.3 \%$, $1.8 \%, 0.4 \%$, and $24.2 \%$ respectively.

(4) Crop planting structure and irrigation system module. This study 
determined the crop structure and irrigation system module using survey result from different canal irrigated planting area and data of "various crops under different irrigation area in Ningxia Irrigation Quota table".

(5) Slope flow module. The study divided the irrigation area into 31 relatively independent fields by the distribution division of surface drainage and natural river runoff flow field range.

(6) Rivers calculation module. The study simulated the river water sinks dynamic by coupling MIKE 11 model and MIKE SHE model, and imported the digitization data of 16 major main canals, 25 major trunk drainage ditches and Yellow River.

(7) Unsaturated Zone module. The study simulated water flow movement of unsaturated zone with simplified two-layer structure of the water balance method.

(8) Saturation band module. According to hydro geological profile and borehole data, the aquifer in the study area was generalized as a single layer structure. And this study identified the hydro geological parameters values of different geological zoning referring to other researches.

\subsection{Calibration and verification of the model}

This study analyzed the sensitive degree of model parameters with water cycle of 2006, selected the parameters to calibrate which had significant affection on the output. Then carried out calibration using data of 2007-2009, and carried out verification using data of 2010-2012. Using the measured data of groundwater level and drains flow as model calibration target, this study evaluated the model results with Naxi efficiency coefficient $(E)$, the correlation coefficient $(R)$ and the mean square error (RMSE).

$$
\mathrm{E}=1-\frac{\sum_{i-1}^{n}(x-y)^{2}}{\sum_{i=1}^{n}(x-\bar{y})^{2}}
$$

$\mathrm{x}$ is the observation, $\mathrm{y}$ is model simulation value, $\overline{\mathrm{y}}$ is average value series of observations, $\mathrm{n}$ is the total number of hours.

$$
\mathrm{R}=\frac{E\{[X-E(X)][Y-E(Y)]\}}{\sqrt{E[E-E(X)]^{2}} \sqrt{E[E-E(Y)]^{2}}}
$$

$\mathrm{x}$ is the observation, $\mathrm{y}$ is model simulation value, $\mathrm{E}$ is the value of expectation. 


$$
\text { RMSE }=\sqrt{\frac{\sum_{i=1}^{n}(y-\bar{x})^{2}}{n}}
$$

$\mathrm{x}$ is the observation, $\overline{\mathrm{x}}$ is average value series of observations, $\mathrm{y}$ is model simulation value, $\mathrm{n}$ is the total number of hours.

The significant affection parameters included unsaturated hydraulic conductivity coefficient, saturated permeability coefficient, specific yield, and drainage coefficient and channel roughness. For the different calculation zones, the rate constant value of each parameter were shown in Table 1

Table 1. the value of calibration parameters

\begin{tabular}{ll}
\hline Calibration Parameters & Values or Ranges \\
\hline unsaturated hydraulic conductivity coefficient & $1.71^{\mathrm{e}-006}$ \\
saturated permeability coefficient & $0.57-2.62$ \\
specific yield & $0.14-0.32$ \\
drainage coefficient & $\mathrm{e}^{-7}-\mathrm{e}^{-6}$ \\
channel roughness & 0.01 \\
\hline
\end{tabular}

This study calibrated the model with data of measured underground water level and drainage ditches flow. The study selected 2 observation wells in central and southern part randomly, and selected first drainage ditch and second drainage ditch which had more connection with agriculture. The fitting water level and drain flow of verification was shown in Figure 1-4.

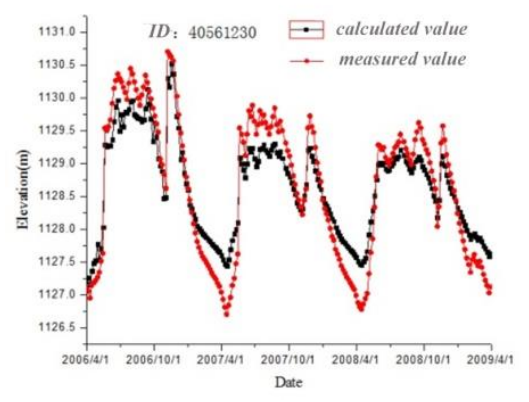

Fig. 1. Fitting figure of well 40561230

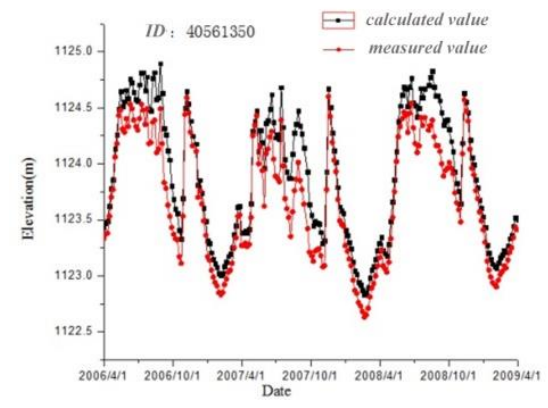

Fig. 2. Fitting figure of well 40561350 


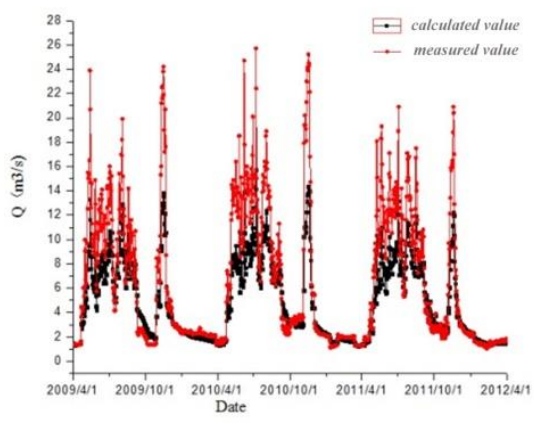

Fig. 3. Fitting figure of first drainage ditch

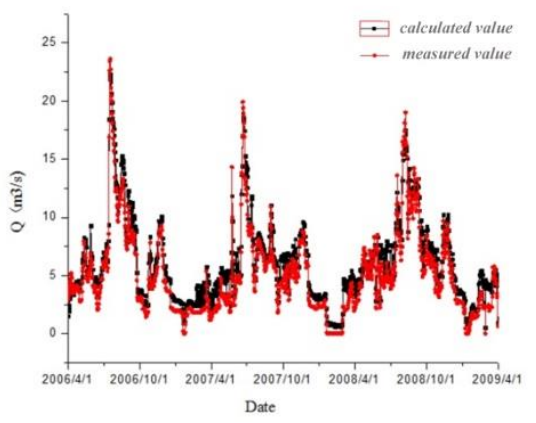

Fig. 4. Fitting figure of second drainage ditch

The value of relevant verification was shown in Table 2 . These results showed that the Nash efficiency coefficient was 0.65 or more, and the accuracy of the model met the demand.

Table 2. The value of relevant verification

\begin{tabular}{llll}
\hline Verify Content & average error & average absolute error & Nash efficiency coefficient \\
\hline well (40561230) & -0.1226 & 0.1226 & 0.7597 \\
well (40561350) & 0.2690 & 0.2690 & 0.6637 \\
first drainage ditch & -1.6110 & 1.6110 & 0.7197 \\
second drainage ditch & 0.2095 & 0.2095 & 0.7911 \\
\hline
\end{tabular}

\section{The Simulation Results and Discussion}

\subsection{The simulation results}

The water balance simulating results of Qingtongxia Irrigation Area was shown in Table 3. From this table, we knew annual average evapotranspiration of Qingtongxia Irrigation Area was 3.537 billion $\mathrm{m}^{3}$, which took up 55.92\% of the total water volume and total precipitation sum; the total drainage ditches flow was about 2.832 billion $\mathrm{m}^{3}$, which took up $44.78 \%$ of the total water volume and total precipitation sum; the groundwater runoff into Yellow River was about 55 million $\mathrm{m}^{3}$, which took up $1.18 \%$ of the total water volume. 
Table 3. The water-cycle model simulation results Unit: $10^{-1}$ billion $\mathrm{m}^{3}$

\begin{tabular}{lcccccc}
\hline Year & Intake & Precipitation & ET & $\begin{array}{l}\text { Surface } \\
\text { runoff into } \\
\text { ditches }\end{array}$ & $\begin{array}{l}\text { Groundwat } \\
\text { er runoff } \\
\text { into ditches }\end{array}$ & $\begin{array}{l}\text { Groundwater } \\
\text { runoff into } \\
\text { Yellow River }\end{array}$ \\
\hline 2007 & 47.33 & 17.84 & 36.63 & 0.71 & 29.58 & 0.60 \\
2008 & 49.33 & 18.08 & 36.08 & 0.63 & 27.28 & 0.54 \\
2009 & 47.77 & 14.67 & 34.41 & 0.63 & 25.53 & 0.50 \\
2010 & 46.50 & 17.99 & 36.43 & 0.71 & 29.27 & 0.58 \\
2011 & 47.14 & 11.97 & 34.40 & 0.47 & 26.83 & 0.54 \\
2012 & 43.79 & 17.10 & 34.28 & 0.67 & 27.63 & 0.55 \\
average & 46.98 & 16.28 & 35.37 & 0.64 & 27.68 & 0.55 \\
\hline
\end{tabular}

\subsection{The Discussion}

This exploratory study built the water-cycle model of Qingtongxia Irrigation Area based on MIKE SHE, carried out simulation, and analyzed the water cycle characteristics quantitatively. For the limitation of professional capacity and research materials, the results still need to be verified.

This study did some generalization or replacement to some sub-model because of data limitations such as material of hydrograph and Channel data, and these researches could do some negative effect to the model accuracy. With the progress of science and technology, we will be able to effectively complement the distributed model modeling data, and further select more reasonable module that could actually reflect the hydrological conditions.

Simulation and analysis had yielded some results, but the test data need to be further fleshed out for the results had not been proved. The data should be extended in further studies to obtain more representative test data, the processing and analysis of data need to be further enhanced.

\section{References}

1. Zhang Xuecheng, Pan Qimin, etc. The Yellow River basin water resources investigation (In Chinese).The Yellow River Water Conservancy Press, 2005;

2. Zhao Zhenguo, Huang Xiuqiao, Xu Jianxin. Advancement in Research of Hydrologic Cycle in Irrigation District (In Chinese).Journal of Anhui Agriculture Science. 2011, 39(26):16080-16081, 16084;

3. JiaYangwen, Wang Hao. An introduction to the research on "Evolutionary Laws and Dualistic Evolutionary Model of Water" (In Chinese). Water Resources and Hydropower Engineering, 2006, 37(2): 45-52.

4. Pei Yuansheng, Zhao Yong, Zhang Jinping, etc. Generalized Theory and efficient use of water resources accounting (In Chinese).Henan: The Yellow River Water Conservancy Press, 2008. 
5. Wan Zen you. Situation domestic application MIKE SHE model and its key issues (In Chinese). Technology Association Forum, 2011, (5): 99-101.

6. Chaplot V. Impact of DEM mesh size and soil map scale on SWAT runoff, sediment, and $\mathrm{NO}_{3}-\mathrm{N}$ loads predictions. Journal of Hydrology, 2005, 312 (1-4): 207-222.

7. DHI 2011, MIKE SHE An Integrated Hydrological Modeling System: User Guide.DHI Software, 2011.

8. Zia Jun, Zuo Qiting. Advances in International Hydrological Science Research (In Chinese).Advances in Earth Science, 2006, 21 (3):256 -261.

9. Zhu Dehua. Application of SHE Modeling to Simulations of History Floods in Liuxihe Basin (In Chinese).Sun Yat-Sen University, 2005. 